\title{
Byssinosis in the Waste Cotton Industry
}

\author{
I. DINGWALL-FORDYCE* and J. G. O'SULLIVAN \\ From the Department of Occupational Health, University of Manchester
}

This paper is of some historical interest. It describes an investigation to determine whether byssinosis occurred among workers in the waste cotton industry. It was undertaken in 1950 at the instigation of the Minister of National Insurance.

The materials used in the industry were (I) cotton that had been previously spun, and (2) waste material discarded during the preparations for spinning higher grades of yarn. A proportion of raw cotton was sometimes blended with the waste.

Twenty-two mills, representative of the industry, were surveyed. All the men in these mills, who were over 35 years of age and with at least Io years' exposure to cotton dust, were seen. The investigations included a work history, a clinical examination, an assessment of effort dyspnoea, and a chest radiograph.

There were 140 men who had never been exposed to any dust hazard other than waste cotton. In this group were found seven $(5 \%)$ men with disabling byssinosis and $35(25 \%)$ men with lesser degrees of the same disease. There were also 15 (1 $1 \%$ ) men with bronchitis or emphysema without byssinosis.

Thus it was established that byssinosis did occur in the waste cotton industry. Insurance cover, under the National Insurance (Industrial Injuries) Act, 1946, was subsequently extended to workers in the waste cotton industry.

The survey provided no evidence that either the type of waste cotton processed or an admixture of raw cotton played a significant part in the aetiology or incidence of the disease.

In March 195 I regulations were introduced whereby certain workers in the waste cotton industry became eligible to receive benefit for byssinosis under the National Insurance (Industrial Injuries) Act, 1946; hitherto only workers in the raw cotton industry had been eligible. These regulations extending the insurance cover were made following an investigation carried out by the Nuffield Department of Occupational Health at the instance of the Minister of National Insurance. Requests have been made that this evidence should be readily available and it is now published with the permission of the Ministry.

This paper is therefore an account of an investigation carried out 15 years ago; it is set in the context of opinion and knowledge current at that time. There have been several subsequent investigations into byssinosis in the raw cotton industry, and the epidemiological approach to this disease has become much more formalized than it was in 1950 . Nevertheless, in the recent clinical study by Massoud

$\star$ Present address: Department of Public Health and Social Medicine, University of Aberdeen.

Received for publication March 19, 1965.
(1964), the approach was very similar to the one adopted in this early investigation.

No attempt has been made to bring the account up to date. It is presented in the original form, which led to the legislation mentioned above. Under the terms of reference the investigation was designed to discover whether byssinosis occurred among workers in cotton rooms, blowing rooms or card rooms in the factories in which the spinning of waste cotton was carried out.

\section{The Waste Cotton Industry $\dagger$}

Because the arrangement and names of workrooms used for the preparation of waste cotton for spinning differed from those of the raw cotton industry, it was thought advisable to give a brief outline of the processes involved.

The cotton processed was of two types, hard and soft waste. The former included various types of waste spun cotton and required special treatment to

†The processes in the waste cotton industry have changed little in the last 15 years. They are substantially the same today as they were when this description was written. 
unravel and tear apart the fibres previously spun to restore them to a soft fleecy state necessary before they could be mixed with soft waste and re-spun. The hard waste was first moved from the warehouse to the 'mixing-room', where a suitable mixture of the various types was fed to a waste-preparing or running-down machine for preliminary opening, and then to the breaking-up machine or 'devil' housed in the devil hole. The devil consisted of three to six cylinders in series; these had revolving teeth which tore apart the threads so that the cotton was restored to a fleecy condition or 'opened'. The fleecy waste was then sprayed with a mixture of soap or oil to correct excessive dryness; this spraying had the added advantage of suppressing dust. The waste was then put in the bin-stack mixer and allowed to become uniformly damp before being fed to scutchers in the scutching room where it was further opened and evened and eventually formed into scutcher laps for processing by the breaker cards.

Soft waste, on the other hand, had never been spun and required no devilling. It consisted of short fibres previously discarded during the preparation of cotton for spinning higher grades of yarn. It was fed from bales into a bale-breaker and passed through opening machines; it was then sprayed with soap or oil and put into a bin-stack mixer to get really damp before being fed to the hopper feeder in the scutching room. After treatment on the finisher scutcher it was removed, as scutcher laps, to the breaker cards in the card room.

The hard and soft wastes were blended at different stages in their processing according to preference in each mill.

The carding machines used were known as 'roller and clearer cards' as against the 'flat cards' of the raw cotton industry. Because they were largely hooded they gave off less dust and were more easily exhausted.

The workrooms included under the terms of reference were the mixing room and devil hole (cotton rooms); the scutching room (blowing room); and card room.

\section{Methods}

Selection of the Sample The investigation was planned to get the necessary information from the smallest number of examinations, which had to be carried out during working hours, and with the least possible interference with production. The examinations were therefore confined to those most likely to be suffering from the disease, i.e., men over 35 years of age who had been employed in cotton rooms, blowing rooms, and card rooms for at least Io years. Men who had been employed in the raw industry were included in the sample because it was important to determine whether or not initial exposure to dust in the raw trade produced a sensitivity which persisted when work was continued in the waste industry. Regulations (at that time) excluded from benefit anyone who had been employed for less than 20 years in the raw cotton industry. Thus a man suffering from byssinosis who had a combined period of service of 20 years in dust rooms in the waste and raw industries, but had had less than 20 years in the latter industry, was not entitled to benefit. Twenty-two mills, representative of various types of waste and different yarns, were selected for study.'

Criteria of Diagnosis Workers in the raw cotton industry in 1950 could, under the National Insurance (Industrial Injuries) Act, receive benefit for byssinosis only if they had a minimum degree of $50 \%$ disablement. The main object of the investigation was to find out if workers in the waste industry should be entitled to similar benefit. Throughout the report, therefore, the term 'byssinosis' was reserved for this, the third, stage of the disease. The first stage, in which a sensation of tightness of the chest and dyspnoea on exertion were experienced on the first day back at work after short absences, was called 'Monday feeling' $\ddagger$ At this stage the symptoms usually lasted for only one day. At the second stage the symptoms gradually became worse and lasted for two or three days. They were, however, largely or completely reversible if the worker was removed from exposure to fine cotton dust; this stage was called 'progressive Monday feeling'. The third stage was that of permanent disabling breathlessness with or without bronchitis.

The diagnosis of 'byssinosis' was considered to depend on three findings: (I) a history of longstanding and progressive 'Monday feeling', associated with exposure to fine cotton dust; (2) a history of constant and progressive effort dyspnoea; and (3) clinical evidence of chronic emphysema causing disablement, with or without chronic bronchitis, and radiological evidence excluding other chest disease.

Assessment of Dyspnoea The assessment of effort dyspnoea was considered to be at once the most important and the most difficult problem. It was approached in two ways, by set questions designed to grade the degree of effort dyspnoea and by a simple exercise tolerance test. Spirometry was thought to be impracticable in this investigation because of the repeated performances necessary to obtain reliable individual results and the consequent increase in the time lost from work.

$\ddagger$ Nowadays called Stage $I$. 
The set questions, modelled on those previously used by the Medical Research Council's Pneumoconiosis Unit, were put to each man twice by two independent observers. The men were allocated to one of five grades according to their answers, regardless of clinical impressions. (It was considered subsequently that this subjective approach had limitations and that a more reliable grading would probably be one based on an experienced observer's assessment of the man's replies and his respiratory condition during the interview.) There was an interval of approximately one hour between the first and second questioning. The same answers were given both times by $90 \%$ of the men; in none of the remainder was there a difference of more than one grade.

The exercise tolerance test (stepping on and off a 13 in. block 18 times per minute for three minutes) was modelled on that described by Hunt (1922) and Campbell (1927). It was simple and likely to reveal major effort intolerance and was therefore chosen as being suitable for a field investigation. Little information of value was obtained from the actual readings of pulse or respiration rates. The exercise test, however, made it possible to observe the patient during and after light exercise and to detect major respiratory distress where this was present. Such respiratory distress, when considered in conjunction with the other findings, frequently resulted in a more confident clinical assessment of the degree of disability and the determination of its cause.

Clinical Grading A clinical grading of the effects of exposure to raw cotton dust, adopted in a preliminary investigation, was found to be of equal value in the waste industry:-

Grade I: Nil. No symptoms present attributable to cotton dust.

Grade II: Untyped Monday feeling. Monday feeling had not progressed and had been present for less than ro consecutive years.

Grade III: Static Monday feeling. Monday feeling had been present for at least ro consecutive years. There had been no advance in severity of these symptoms, which were still confined to the first day back at work.

Grade IV: Progressive Monday feeling. Monday feeling had become more severe or was no longer confined to the day of return to work.

Grade V: Disabling 'byssinosis'. Disabling byssinosis was characterized by constant effort dyspnoea, due to emphysema and causing a disability of not less than $50 \%$. Exposure to fine cotton dust exacerbated the symptoms of progressive Monday feeling.

The term 'Monday feeling' was applied to the symptoms which arise in susceptible operatives in the early stages of byssinosis. The account of those symptoms was so constant in cases of byssinosis that an intimate knowledge of the Monday feeling was essential for the diagnosis of this disease.

Some one to six hours after beginning work on Mondays the affected worker notes a tightness of the chest and shortness of breath which make physical effort more difficult. This commonly increases in degree until he leaves the mill. $\mathrm{He}$ is then abnormally tired and dyspnoea notably slows his progress uphill as he walks home. He prefers to sit and rest for an hour before his evening meal. He may in addition have a definite nocturnal orthopnoea which demands an open window and an extra pillow on Mondays only. Cough in the early years of the affection is often absent and, where present, is usually dry, tickling, and paroxysmal. This 'Monday feeling' of the first few years had, in the majority of cases, completely cleared by Tuesday morning, only to reappear on the following Monday. In other cases, some symptoms remain on Tuesdays but always in lesser degree and they clear steadily as the days pass by. Workers affected by the 'Monday feeling' experience it in greater degree where absence from work has been longer than a week-end, and some who are unaffected by the week-end break have this same 'Monday feeling' after the longer holidays. It is of interest that some men experienced increased symptoms after the introduction of the five-day week, whereas another, who continued work over Saturday and Sunday every third week, was free from symptoms only after that week-end.

Chest Radiographs Chest radiographs could not be used to make a positive diagnosis of byssinosis since there were no constant radiological pictures pathognomonic of the disease. However, it was considered that they were of value to exclude other respiratory disease, which might imitate disabling byssinosis.

\section{Results}

'Byssinosis' In the selected sample of 22 mills, there were 185 men who were 35 years of age and over who had worked in dust rooms for at least Io years. Of these, three had left the dust rooms and were working elsewhere in the mill at the time of the investigations and 42 had been exposed to other dust hazards. The remaining 140 men were working in dust rooms at the time of examination and had never been exposed to any dust hazard other than waste cotton. To comply with the main object of the investigation attention was focussed primarily on these men. 
There were seven cases of byssinosis grade $\mathrm{V}$ in this group; 35 men were found to have lesser degrees of cotton dust respiratory disease, and 98 showed no evidence of this disease in any of its stages.

A group of 103 men, comparable in age and length of exposure, who were working in the raw cotton industry had been examined during a preliminary survey. Details of the findings in the two groups are given in Table I.

TABLE I

\begin{tabular}{|c|c|c|c|c|}
\hline \multirow[t]{3}{*}{ Grade } & \multicolumn{4}{|c|}{ No. of Men in Grades } \\
\hline & \multicolumn{2}{|c|}{ Waste Cotton } & \multicolumn{2}{|c|}{ Raw Cotton } \\
\hline & No. & $\%$ & No. & $\%$ \\
\hline I & 98 & 70 & 39 & 38 \\
\hline II, III, and IV & 35 & 25 & 54 & 52 \\
\hline V & 7 & 5 & Io & IO \\
\hline
\end{tabular}

No difference could be detected in the clinical picture as seen in the raw and waste cotton industries; it was in fact the same disease. However, there was a significantly greater incidence of 'byssinosis' in the raw cotton industry $(\chi=24.7$; $\mathbf{P}<0.001$ ).

Clinical Findings The examinations were carried out during warm, dry weather. No finger clubbing was found throughout the sample. Major effort dyspnoea, diminished air entry, and dorsal kyphosis were the most prevalent clinical abnormalities in grade $\mathrm{V}$. Abnormality of the sternum and a hyper-resonant percussion note or adventitious sounds were present in less than half of these cases of disabling byssinosis. Of those in grade I, $18 \%$ had physical signs of bronchitis or emphysema. Further details are given in Table II.

Clinical Diagnoses Clinical diagnoses of various chest conditions were made among the 98 men in grade I (no symptoms attributable to cotton dust). Fifteen were diagnosed as suffering from bronchitis or emphysema; one other had asthma. Thus in the group of 140 men, $5 \%$ were diagnosed as having disabling byssinosis and $I 1 \%$ as having bronchitis or emphysema without byssinosis or earlier manifestations of the same disease.

Chest Radiographs Chest radiographs were taken of $98 \%$ (137) of the group; the remaining three men were all in grade I. Four men in grade I showed evidence of old tuberculosis requiring further investigation to exclude activity; there was no evidence of active tuberculosis among the 42 men in the other grades.
TABLE II

Clinical Findings

\begin{tabular}{lll} 
Clinical Findings & \multicolumn{3}{l}{ Grade } \\
\cline { 2 - 4 } & \multicolumn{1}{l}{$\begin{array}{l}I I, I I I, \\
\text { and IV }\end{array}$} & $V$ \\
\hline
\end{tabular}

\begin{tabular}{lrrr}
\hline $\begin{array}{l}\text { Spine, dorsal kyphosis with or } \\
\text { without scoliosis }\end{array}$ & 12 & 3 & 6 \\
$\begin{array}{l}\text { Sternum, abnormal } \\
\text { Finger clubbing }\end{array}$ & 12 & 0 & 2 \\
Chest, abnormal in any detail & 0 & 0 & 0 \\
$\quad$ & 18 & 14 & 7 \\
specified below: & 7 & 9 & 4 \\
Breath sounds, abnormal & 13 & II & 3 \\
Adventitious sounds & 4 & 2 \\
Percussion, hyperresonance & 5 & 8 & 6 \\
Air entry diminished & 18 & 35 & 7 \\
Total no. in group & 98 & 35 &
\end{tabular}

Physical Type Men who were definitely of the long-necked, asthenic or the short-necked, obese type were classified as such. No evidence was found to suggest that the latter were more liable to develop byssinosis than those of other builds. Thirty-five percent (25) of the long-necked asthenics, 30\% (12) of the short-necked obese, and $27 \%$ (19) of those who were unclassified were in grades II to V.

A definite history of the date of onset of Monday feeling was obtained from 31 of the 42 men in grades II to V. One man developed it immediately on entry to the blow room; his symptoms had remained constant and had not progressed for the subsequent 18 years. In general the length of exposure to dust hazard before the onset of Monday feeling varied considerably. It ranged from this immediate onset to 36 years; the mean time was I7.9 years.

Type of Material Processed The type of waste cotton processed did not appear, in this sample, to play a significant part in the aetiology or incidence of byssinosis. The predominant materials which had been used by the seven 'byssinotics' were high-grade soft waste and hard waste.

Mixtures of Raw and Waste Cotton Details of the incidence of the disease in relation to the proportion of raw cotton used are given in Table III.

This analysis yielded no evidence that, in these quantities and under these conditions, raw cotton was a significant factor in the aetiology or incidence of the disease. This was of especial interest as the practice of mixing a small proportion of raw cotton with the waste was tending to become more general throughout the industry because of the decreasing amount of waste cotton available. 
TABLE III

Number of Men AfFected According to the Proportion of RAW COTTON USED

\begin{tabular}{|c|c|c|c|c|c|c|}
\hline \multirow[t]{3}{*}{ Grade } & \multicolumn{6}{|c|}{ Raw Cotton Used (\%) } \\
\hline & \multicolumn{2}{|l|}{ Nil } & \multicolumn{2}{|c|}{ I-I9 } & \multicolumn{2}{|c|}{$20-36$} \\
\hline & No. & $\%$ & No. & $\%$ & No. & $\%$ \\
\hline I & 55 & 69 & $2 I$ & $8 I$ & 22 & 63 \\
\hline $\begin{array}{l}\text { II, III, and IV } \\
\text { V }\end{array}$ & $\begin{array}{r}18 \\
6\end{array}$ & $\begin{array}{r}23 \\
8\end{array}$ & $\begin{array}{l}5 \\
0\end{array}$ & $\begin{array}{r}19 \\
0\end{array}$ & $\begin{array}{r}12 \\
1\end{array}$ & 34 \\
\hline All grades & 79 & 100 & 26 & 100 & 35 & 100 \\
\hline
\end{tabular}

Symptoms of Respiratory Disease Due to Cotton Dust Found Among Total Sample Details of the findings among the total number examined (185) are given in Table IV. Inquiries

TABLE IV

Findings Among the Total Number Examined

\begin{tabular}{lclll} 
Grade & \multicolumn{3}{l}{$\begin{array}{l}\text { Occupational Dust } \\
\text { Only } \\
\text { Waste }\end{array}$} & $\begin{array}{l}\text { Hotton } \\
\text { Had } \\
\text { Worked }\end{array}$ \\
\cline { 2 - 5 } & $\begin{array}{l}\text { In Dust } \\
\text { Room }\end{array}$ & $\begin{array}{l}\text { Ex Dust } \\
\text { Room }\end{array}$ & $\begin{array}{l}\text { Raw } \\
\text { Cotton }\end{array}$ & $\begin{array}{l}\text { Other } \\
\text { Dust } \\
\text { Hazard }\end{array}$ \\
\hline I & 98 & 0 & 20 & 9 \\
II, III, and IV & 35 & 1 & 9 & 3 \\
V & 7 & 2 & 0 & I \\
All grades & 140 & 3 & 29 & I3
\end{tabular}

were made at all mills for men who had left the dust rooms, for health or other reasons, and were working elsewhere in the mill; three men were found in this category.

In this survey there was no indication that previous exposure in the raw industry had influenced the incidence of byssinosis or earlier stages of this disease.

\section{Conclusions}

Examination of 140 men, whose only exposure to dust had been in the dust rooms of waste cotton spinning mills, revealed seven cases of 'byssinosis' with a constant disability of not less than $50 \%$. Thirty-five men (25\%) were found to have lesser degrees of the same respiratory disease.

This finding led to an extension of insurance cover under the National Insurance (Industrial Injuries) Act, 1946 to workers in the waste cotton industry.

Other findings had emerged during the inquiry and were thought to be of sufficient interest to include in the report.

Although the disease did occur to an appreciable extent in the waste industry, the incidence was found to be significantly less than the incidence in the raw cotton industry.

-Fifteen men ( $I I \%)$ were diagnosed as having bronchitis or emphysema without 'byssinosis' or earlier manifestations of this disease. It was considered that the characteristic symptomatic history of byssinosis provided sharp differentiation from chronic emphysema, chronic bronchitis or chronic asthma of other origin-conditions which might occur alike in cotton workers and in the general population.

There was no evidence that the proportions of raw cotton used in the waste mills included in the survey had an effect on the incidence of byssinosis.

This inquiry was carried out at the request of, and financed by, the Ministry of National Insurance.

We wish to thank Professor R. E. Lane and Dr. (now Professor) R. S. F. Schilling for their direction and help throughout the investigation; Dr. Charles Fletcher and other members of the Medical Research Council's Pneumoconiosis Research Unit, who undertook the radiological survey; members of the Condenser and Allied Spinners' and Manufacturers' Association and officers of the Amalgamated Association of Card and Blowing Room operatives for their support; and the individual mill managers and workmen for their co-operation.

\section{REFERENCES}

Campbell, J. M. H. (1927). Guy's Hosp Rep., 77, 184 . Hunt, G. H. (1922). Ibid., 72, 347.

Massoud, A. (1964). Brit. f. industr. Med., 21, 162. 